\title{
Study on the Meaning of Chinese Traditional Cultural Resources to the Construction of Chinese Indigenous Management Theory
}

\author{
Based on the Perspective of Experiential Foundations
}

\author{
Shuwang Zhang \\ School of Public Administration \\ South China University of Technology \\ Guangzhou, China 510641
}

\author{
Qianting Lu \\ School of Public Administration \\ South China University of Technology \\ Guangzhou, China 510641
}

\author{
Jeff Wang* \\ School of Social Work \\ Rutgers The State University of New Jersey \\ New Brunswick NJ 08904 US \\ *Corresponding author
}

\begin{abstract}
Through the research on the construction of Chinese philosophy and management theory in recent years, this article focuses on the relationship between Chinese indigenous management theory and Chinese traditional cultural resources. The research indicates that management scholars summarize laws and construct new theories as the man of experience in life-word rather than the rational man. It is life-word rather than the pure ethnic philosophical theory that should be the cornerstone when constructing Chinese indigenous management theory. On the basis of experience, Chinese indigenous management theory can dialogue and mutual interpretate equally with western mainstream management theory.
\end{abstract}

Keywords-indigenous management theory; theoretical construction; man of experience; life-world; disciplinary nature; mutual interpretation between chinese and western

\section{LITERATURE REVIEW AND RAISING THE QUESTIONS}

Since 2004, Chinese management scholars have been reflecting on the management researches and practice from the period of reform and opening-up, and trying to sum up the development path to the Chinese indigenous management. Nowadays, I found out that the research approaches to Chinese management theory were in a mess of theme confusion, academic diffident and concept definiting problems when they were put forward in the beginning. But today, Chinese indigenous management theory turns to be accepted by most of Chinese management scholars; what's more, its development has accessed to the stage of theoretical

The paper is Supported by the project of National Natural Science Foundation of China (71572060); by the project of Guangdong's "12th Five-Year Plan" of social science (GD11CZZ02); by the Major project of the Ministry of Education (16JZD026); by the project of Guangzhou's "13th Five-Year Plan" of social science (2017GZYB40). affirmation from the stage of theoretical nagation, and has entered a new research situation of philosophical foundation from the discussion about concepet definition and technical route.

For the development strategy of Chinese indigenous management theory, academician Guo Chongqing (2008) has put forward a proposition named "indomitable spirit". He pointed out that the development path to Chinese management should be from "repeating narration" to "developing narration": "As for how to be ' developing narration ', it can cite the Chinese philosophy's development path, put forward by Mr. Tang Yijie: it should be developed from Chinese traditional culture, from western management and from Chinese management practice." Throughout the development process of Chinese indigenous management, its mainstream research paradigms are developed "from western management" and "from Chinese management practice". The paradigm "from western management" means it regards western management paradigms as its standards and develops the Chinese management theory with western management topics; and the paradigm "from Chinese management practice" means it takes the practice of Chinese enterprises as its research objects and develops the Chinese management theory with the existing norms of western social science. However, compared to these two paradigms, only does the research paradigm "developed from Chinese traditional culture" seems to have not formed a significant academic climate yet, although it has a not short history with some mature and normative management schools (Peng $\mathrm{He}$ and Su Weizong, 2006; Peng He and Liu Wei, 2006). The reasons for such a situation are not only related with the social environment, but also with the lack of research on the 
Chinese tradition on the growing process of the academic community.

Professsor Li Ping led a discussion about the relationship between Chinese indigenous management theory and Chinese traditional philosophy, which opens a new page for the philosophical basis of Chineses indigenous management theory. In this discussion, Li Ping (2013) argued that "the research on Chinese indigenous management must strive root in Chinese traditional philosophy." $\mathrm{He}$ advocated of constructing the Chinese indigenous management with Chinese traditional philosophy's elements, such as Taoism (道), Yin and Yang (阴阳), Wu (悟) and so on, which aroused opposition from many other scholars. Thus, here come the questions. Can the elements of Chinese traditional philosophy become indigenous management theory's directly? And what is the philosophical basis of Chinese indigenous management?

\section{THE INITIAL RESEARCH OBJECT OF CHINESE} INDIGENOUS MANAGEMENT SHOULD BE COUNTRYMEN'S MANAGERIAL EXPERIENCE

\section{A. Debate on the scope of management research}

From the perspective of research objects, most of the scholars consider that management should include human, financial and material resources.But there are always different points. Harold Koontz (1961) contented it that: "In defining the body of knowledge, care must be taken to distinguish between tools and content. Thus, mathematics, operations research, accounting, economic theory, social metrology, and psychology, to metion a few, are significant tools of management but are not, in themselves, a part of the content of the field."

Fayol excluded other technical activities in his masterpiece and defined the management as 5 functions in the organization, Professor Tan Liwen(2009) also defined the research objects of management as the human social activities excluding the material management. "So we can conclude a simple definition to the management : it is a social activity in an organization, which is to coordinate the difference between individual and organizational goals and achieve the purpose of improving organizational effectiveness and efficiency.(Tan Liwen, 2009)" In the broadest sense, what general management studys is not only about human, but also about some other elements, such as material, technology, time and so on.(Lin Xi, 2006) But the special management which Kontz stands for is defined as a management only about human. In a word, making a distinction between general management and sepecial management helps to illustrate the research objects of the Chinese indigenous management from the perspective of philosophical foundation.

\section{B. Management Experience Is the Intermediary between Management Practice and Management Theory}

Special management defines management as the human social activities. So how do people act in this kind of management? Does the management practice hasten the birth of management theory directly?Herbert Alexander
Simon(1997) considered that people are of bounded rationality, and managers' decision-making and behaviour depend on two models-"hesitation-choice" and "stimulusresponse". He found that when people come to a dicisionmaking situation, they seldom choose the "hesitation-choice" model, aka the rational model, which needs to consider each factor and condition carefully. In contrast, most of them will choose the "stimulus - response" model, aka the empirical model, in which people make a decision by reminding themselves of the past empirical path according to the similarity of the current events. The empirical model is simple, rapid, and has an extremely high practicability. The thought that people seldom use rational model instead of empirical model is also supported by Henry Mintzberg (1973). In his thought, only little managers' behavior is carefully considered in reality. Most of management work is based on experience to make an intuitive and rapid decision. This perspective of practice-experience is often pointed out by some researchers in "management in China". As Scholar Lv Li(2011) said that:"The profit mode of e-commerce, the method of kanban management of Toyota Corporation and so on don't look like that they are derived from management science. They're more similar to the combinations of experience, culture and inspiration."

The scholars' opinions mentioned above seem to prove that practice produces experience, experience guides practice, and much more experience can produce management theory (aka the practice-experience-theory-practice path), instead of proving that practice produces theory and theory guides practice (aka the practice-theory-practice path). Experience seems to be a necessary intermediary between practice and theory.

\section{Three Mechanisms of Management Experience to Guide Practice}

Experience is a human creation, which is the consensus of the academic community. But how does experience guide practice ? After some psychological tests, Elsterl.J and Kahneman (1974) confirmed that personal dicisions are often adopted with "empirical estimation", which means people judge subjectively according to the probability criterion of experience, instead of the "rational model" assumed by economics and management. Besides, they even found that when empirical model and rational model have a great difference between each other, most of people will choose the former one. Most importantly, they believed that "experience" gudies practice with three mechanisms: representative mechanism, associational mechanism, and selective mechanism.

Representative mechanism shows that the judgement of object A is often depended on object B which is similar to object $A$. The causal mechanism of object $A$ is transplanted from object B's. The connection between A and B is up to how similar they are. This mechanism points out that after storing a number of classic cases in mind, actor will make a decision for the current event based on the experience of classic cases. And this is the primary mechanism how experience guides practice, especially decision-making. 
What associational mechanism means is how people guide practice is not to find out the classic cases by probability theory, but to form an association in accordance with the extent of the psychological association of such phenomena. The guidance experience is mainly from the case experience which is associated easily.

Selective mechanism shows that in a situation with abundant empirical datas, actor will not make a conclusion by statistical analysis, but will infer a conclusion by choosing the easiest route in their first impression. It is also known as data interception by fixed impression.

It can be concluded that representative mechanism is the main component of experience while associational mechanism and selective mechanism are the main ways for reprsentative case to guide practice. Representative case is an artificiality formed by actor's deep cultral structure, which is the interaction between their ethnic philosophy and behavioral experience. Besides, associational mechanism and selective mechanism reflect the fixed cognitive model and value preferences behind them.

\section{The SUBJECt NATURE OF MANAGEMENT BASED ON EXPERIENCE}

\section{A. The Dual Legitimacy of Management}

The development history of management is the history of its debate on subject nature. In my opinion, the nature of one subject should be studied from the perspectieve of phylogenetics firstly. Most founders of management were enterprise managers and where they studied were enterprises rather than universities. Therefore, the subject nature of management is an applied science, which faces to management practice and is founded on abundant experience.

The place where the management knowledge was created was changed to universities from factories. And in order to get its universities' legitimacy admitted, the research methods of management begun to imitate the mature methods of natural science, pursue the rigorous axiom and the deductive logical system. Thus, the basic research paradigm of management is that one research puts forward the hypothesis according to the existing theoretical premise, then deducts in the logical system to draw a new theoretical proposition, and finally verifies the theoretical hypothesis and proposition in an empirical method. This paradigm is believed that this kind of method can put forward a causality which has general significance in management science (Zhou Xueguang, 2003). And as soon as the same condtions are found, this method can also predict the results accurately like how the natural science does. However, this research paradigm of management succees rarely in reality and is impossible to predict the results in accuracy. Under this paradigm's guidance, more rigorous the management science becomes, more far away from its original intention to guide practice it will be. As a result, management science gains its unniversities' legitimacy, but meanwhile, it loses its social legitimacy as well, so finally become an intelligence game among professors.

\section{B. The Analysis of Management Science's Utility Scope}

Although the research of management theory can't meet the requirement of scientism's universality, it doesn't mean that it is invalid and worthless to analyze and explain the issues and the phenomenons in management. Merton(1952) believed that social science theory have to give up the fantasy of universality. And he puts forward the middlerange theory which discusses the research scope between universality theory and individual empirical proposition. In other words, the middle-range theory discusses the research of building a law mechanism among a selected group. This selected group can be a kind of organization, a nationality, a regional life group and so on.

Elster(1998)considered that if there is a recurrent and recognizable causality existing among the groups, it can be sure that these two things have causality. This causality is non-individual, non-uniform but probabilistic. Owing to both reason and result in this causality can't be accurate to individual, so that it can't be a decisive and inevitable causality. And management research is such a kind of causality like that. For example, paternalistic leadership among Chinese groups which use kindness and authority to lead their subordinates is effective. According to the research, we can know that this mechanism happens frequently, observable and recognizable, but it is not inevitable. We can give an explanation to paternalistic leadership about why it is effective, but we can't forecast that if each paternalistic leadership is effective to their subordinates or not. Therefore, the level which the management research can reach is to analyze and explain the problems from the observable management phenomenon and make the causal mechanism effective in a definite range rather than pursuing its preciseness and logicality.

Management science is a causal mechanism based on groups' experience. Because the multiplication of experience is ambiguous, the regular pattern of experience has its probability which is unable to make an accurate prediction in scientism. Management research also has its group-character, which is allowed to study the management causal mechanism in only one group. Once it has more than one group, its causal mechanism is ineffective. That's why some management scholars find some management theories ineffective when they are interculturally applied.

\section{THE RESEARCH OBJECT OF CHINESE INDIGENOUS MANAGEMENT IS LIFE-WORLD RATHER THAN PHILOSOPHICAL THEORY}

The life-world of historical continuity is the sum of all Chinese experience.There is an important experience needed to be taken seriously when Professor Huang Guangguo was constructing the indigenous psychology: "during analysing culture, we must separate two things from each other, one is cultural system, and the other one is the interaction of social culture. The culture or the thought that philosophers sorts out and put forward initially is a cultural system. After it was put forward, each generation will reinterpret the cultural system in their enthic historical developing process. 
And what they reinterpret is the interaction of social culture.(Huang Guangguo, 2014)"

A set of concepts in Chinese philosophy is involved here : ideal world and life-world. The cultural system is an ideal world and the interaction of social culture is a lifeworld. Chinese cultural system consists of various academic systems founded by hundred schools of thought in pre-Qin times and some theorists in the later ages, which mainly includes Confucianism, Buddhism and Taoism. There are two reasons for being an ideal world. Firstly, there are classics as carriers. Secondly, there are followers who are faithful to cultural system. Mencius said that: "if there is morality and justice in the world, we use them to guide our life; or if not, we fight for them with our lives."(Li Ping, 2010) Professor Yu Yingshi(2003) believed that: "the men who take morality and justice as his responsibilities cherish such a moral idealistic spirit. What they do and what they think are beyond their individual or groups' interest and concerned about the whole society with a strong faith which is similar to a religious belief." However, this lifestyle still belongs to minority and can't constitute the integral national life-experience.

The life-world, Husserl Edmund explained it as a world with original self-evidence. Before realizing the science knowledge, human accumulated experience in everyday life to make a variety of interpretations, combinations, and responses. Life-word is a pre-logic, pre-technical and preinstrumental ontological realm, whose abundance is rooted in individual direct life-experience.(Huang Guangguo, 2013) After the Song Dynasty, Chinese culture comes to a syncretism of three religions. In this period, Confucianism, Buddhism, Taoism are unified into the neo-Confucianism which becomes a mainstream value afterwards. It constituted the preexistent circumstance that every individual Chinese have to study and accept, and also formed a national integral life-experience. This experience integrates into Chinese culture and contains Chineses value and structure, which is an output brought by internal culture system and external circumstances.

\section{CONCLUSION AND EXPECTATION: THE MUTUAL INTERPRETATION BETWEEN CHINESE AND WESTERN EXPERIENCE CAN BE A PHILOSOPHICAL METHOD TO CONSTRUCT CHINESE INDIGENOUS MANAGEMENT THEORY}

In Professor Huang Guangguo's opinion (2013): “the development of Indigenous psychology is to solve the problems in philosophy of science rather than in psychology. We can't make a breakthrough without understanding the philosophy of science" I agree with that so much bacause this experience is applicable to Chinese indigenous management. To develop Chinese indigenous management theory, the lack of philosophical basis, especially the epistemology basis needs to be solved. How to solve this problem makes a challenge for the Chinese indigenous management researchers. Disapointedly, most of scholars still keep using ontology, epistemology and methodology to analyze indigenous cultural phenomenons, which impedes their development.
In fact, contemporary western philosophy has taken up analyzing artifact like language and stream of Consciousness rather than Realism, and enter an age of studying phenomenology and hermeneutics. It is necessary for Chinese indigenous management researchers to know how to make a mutual interpretation between Chinese and western experience with the research attitude and methods of phenomenology, which helps to make the communication between Chinese and western culture smooth. So here comes an example. After doing researches on Chinese Mindphilosophy, European phenomenologist Geng Ning(2012)refered that: "it's amazing that after two thousand years, some Mencius' Concrete examples about sympathy can be understood and comprehended by western in a total different cultral background. What Mencius put forward seems to be a human nature." In Geng Ning's views, the basis of mutual interpretation between Chinese and western culture is the cultural experience. So as long as we get confidence in our culture, dialogue with other culture equally, and consciously learn from other civilizations' experience, definitely we can expand the theorical vision of Chinese indigenous management and accelerate the formation of its own theory.

\section{REFERENCES}

[1] Geng Ning. Meng Zi, Adams Smith and Husserl on Sympathy and Conscience [M], Beijing: Commercial Press, 2012.

[2] Guo Chongqing. The Social Responsibility and Historical Mission of China Management Science Academe[J]. Chinese Journal of Management, 2008(03): 320-322.

[3] Huang Guangguo. The logic of Social Science [M], Taipei: Psychology Press, 2013.

[4] Huang Guangguo, Luo Jiade, Lv Li. Key Issues in the Study of Indigenous management in China -- interviews with Huang Guangguo and Luo Jiade, 2014(10): 1436-1444

[5] Li Ping. Indigenous studies of Management in China: Concep Definition and Paradigm Design [J]. Chinese Journal of Management, 2010(05): 633-641.

[6] Li Ping. Indigenous Research on Chinese Management and Chinese Traditional Philosophies[J]. Chinese Journal of Management, 2013(09): 1249-1261.

[7] Lin Xi, Discipline Attribute and Discipline Orientation of Management [J]. Management and Review of Social Sciences, 2006(03): 88-96.

[8] Lv Li. Meta-Issues of Management and Management Philosophy: Discussion on Logic Defect of The Forecast: Facing the Chinese Management Practice [J]. Chinese Journal of Management, 2011(04): 517-523.

[9] Lv Li. How Can Management Be Practice-Oriented: Management Technization and Its Methodology [J]. Chinese Journal of Management, 2011(06): 796-804.

[10] Lv Li. Management and Ideology: Discussion with Li Ping on Power of Discourse in the Chinese Management Research [J]. Chinese Journal of Management, 2011. 08(1): 28-36.

[11] Peng He, Su Zongwei. Oriental Management Theory: Its Source, Essence and Framework [J]. Chinese Journal of Management, 2006(01): 12-18.

[12] Peng He, Liu Wei. The Discipline Development Situation and the Future Prospect about Oriental Management[J]. Chinese Journal of Management, 2006(05): 629-630.

[13] Tan Liwen, On Constructing Generally Applicable Management Theory [J]. Chinese Journal of Management, 2009(03): 85-290. 
[14] Yu Yingshi.Scholar and Chinese culture[M]. Shanghai: Shanghai People's Publishing House, 2003.

[15] Zhou Xueguang. Ten Lectures on Organizational Sociology [M]. Beijing: Social Sciences Academic Press, 2003.

[16] DANIEL K, SLOVIC P, TVERSKY A. Judgment Under Uncertainty: Heuristics and Biases [J]. Science, 1974(4157): 1124-1131.

[17] ELSTER1, J. Social Mechanisms: An Analytical Approach to Social Theory [M]. Cambridge: Cambridge University Press, 1998.

[18] Herbert A. Simon. Administrative Behavior [M]. New York: Free Press, 1997

[19] KOON TZ H. The Management Theory Jungle[J]. The Journal of the Academy of Management, 1961, 4(3):174-188.

[20] Robert K. Merton. Reader in Bureaucracy[M].Glencoe: Free Press, 1952.

[21] MINTZBERG H. The Nature of Managerial Work [M]. New York: Harper \& Row Press, 1973. 